\title{
Coulomb per Square Meter
}

National Cancer Institute

\section{Source}

National Cancer Institute. Coulomb per Square Meter. NCI Thesaurus. Code C68911.

A unit of electric charge density used to express a number of lines of electric force

emanated or absorbed by an electric charge equal to one coulomb per unit area equal to one square meter. 